\title{
SUCESSO E FRACASSO NO ENSINO DA MATEMÁTICA: O QUE DIZEM FUTUROS PROFESSORES DE UMA IES? ${ }^{1}$
}

\section{SUCCESS AND FAILURE IN MATHEMATICS TEACHING: WHAT SAYS FUTURE TEACHERS OF AN IES?}

\author{
Valéria Maria de Lima Borba ${ }^{2}$ \\ André Pereira da Costa ${ }^{3}$
}

\begin{abstract}
Resumo: Este estudo objetivou discutir sobre os fatores que contribuem para o sucesso e o fracasso nos cursos de Licenciatura em Ciências e Matemática de um centro acadêmico vinculado a uma Instituição de Ensino Superior (IES) do Estado da Paraíba, Brasil, a partir da compreensão dos licenciandos sobre tais elementos. Assim, buscou-se analisar se estes fatores interferem na permanência e no abandono dos estudantes em seus cursos universitários. Com uma abordagem qualitativa, a pesquisa fez uso de um questionário como instrumento de coleta de dados, que foi aplicado a 22 licenciandos. Os estudantes questionados, em sua grande maioria, colocam a referência para o sucesso basicamente no esforço próprio, salientando a dedicação e a perseverança próprias. Quando se discute a relação que os licenciandos estabelecem com o fracasso, vários foram os fatores considerados como deflagradores dos insucessos ocorridos, com considerável peso na didática utilizada pelos seus professores.
\end{abstract}

Palavras-chave: Matemática; Formação de Professores; Fracasso; Sucesso.

\begin{abstract}
This study aimed to discuss the factors that contribute to success and failure in the degree courses in Science and Mathematics of the academic center linked to an Institution of Higher Education (IES) in the State of Paraíba, Brazil, through students' understanding of such elements. Thus, it was sought to analyze if these factors interfere in the permanence and the abandonment of the students in their university courses. With a qualitative approach, the research made use of a questionnaire as an instrument of data collection, which was applied to 22 graduates. Most of the questioned students place the reference to success primarily in their own effort, emphasizing their own dedication and perseverance. When discussing the relationship that the students establish with failure, several factors were considered as triggers of the failures occurred, with considerable weight in the didactic used by their teachers.
\end{abstract}

Keywords: Mathematics; Teacher Training; Failure; Success.

\section{Introdução}

Esta pesquisa busca discutir sobre os fatores que contribuem para o sucesso e o fracasso nos cursos de Licenciatura em Ciências (Habilitação em Matemática) e Matemática de um centro acadêmico vinculado a uma Instituição pública de Ensino

\footnotetext{
${ }^{1}$ Este artigo apresenta alguns resultados de um projeto de pesquisa, que foi desenvolvido em um centro acadêmico vinculado a uma IES da Paraíba, entre os anos de 2011 e 2013. Outros resultados desse estudo podem ser encontrados em Lima Borba e Costa (2013a; 2013b).

${ }^{2}$ Doutoranda em Ensino das Ciências e Matemática pela Universidade Federal Rural de Pernambuco (UFRPE), Mestra em Psicologia Cognitiva pela Universidade Federal de Pernambuco (UFPE). Professora Assistente da Universidade Federal de Campina Grande (UFCG), Cajazeiras, Paraíba, Brasil. E-mail: valbo66@yahoo.com.br

${ }^{3}$ Doutorando e Mestre em Educação Matemática e Tecnológica pela Universidade Federal de Pernambuco (UFPE). Professor de Matemática na rede pública estadual de Pernambuco, Recife, Pernambuco, Brasil. E-mail: andre.pcosta@otlook.com
} 
Superior (IES) do Estado da Paraíba, Brasil. Tais fatores interferem, direta ou indiretamente, para um provável rompimento que se sinaliza na conduta matemática dos estudantes ingressantes nos cursos citados, gerando um comprometimento da atuação dos licenciandos que principiam esses cursos.

Contudo, os problemas que se referem à desistência e ao baixo desempenho nos cursos da área de Matemática não ocorrem somente na referida IES, mas em diversas instituições de ensino brasileiras e estrangeiras, que também identificaram tal fenômeno.

Os fatores geradores desse cenário no ensino superior são diversos. Para alguns, a baixa qualidade do ensino da Matemática na educação básica pode ser o principal responsável; outros sinalizam que a formação dos professores de Matemática que atuam na escola básica e na universidade está obsoleta (RAFAEL, 2015). Há ainda aqueles que alegam que as metodologias utilizadas pelos docentes universitários em sala de aula são inadequadas, e que a falta de diálogo entre os conteúdos matemáticos e a prática social pode favorecer o desestímulo e o posterior fracasso de estudantes que estudam Matemática, em cursos superiores (LIMA BORBA; BRITO LIMA; RÉGNIER, 2015). Certamente, existem outros motivos causadores desse fenômeno que não foram mencionados, mas que também merecem ser discutidos e analisados.

$\mathrm{Na}$ tentativa de reverter tal situação, várias instituições de ensino superior disponibilizam programas de monitoria, cursos preparatórios, disciplinas em períodos de verão, elaboração de material didático-pedagógico, cursos complementares, como por exemplo: matemática do ensino médio, com o intuito de rever conteúdo do ensino médio que não foram compreendidos, etc. Embora algumas universidades tenham conseguido alguns resultados satisfatórios, muitas dessas soluções não são transferíveis para outros contextos.

Para tanto, nosso interesse pelo tema se explica pelo fato de as disciplinas de Matemática nos cursos superiores apresentarem elevados e progressivos índices de reprovação e evasão (RISSI; MARCONDES, 2011; RAFAEL; ESCHER, 2015), necessitando, dessa forma, de uma busca contínua por justificativas de tal problema. Destarte, refletiremos a luz da Psicologia da Educação Matemática e da Didática da Matemática sobre os prováveis agentes causadores e ainda as possíveis soluções para a problemática em pauta.

Logo, este trabalho pretende também lançar uma luz sobre o tema e suas problemáticas. 


\section{Reflexões e usos sociais da Matemática}

A importância da Matemática no processo de humanização e da construção da cidadania é inquestionável, uma vez que se utiliza a Matemática desde as mais corriqueiras às mais complexas atividades, em contextos escolar e extraescolar. Portanto, torna-se imprescindível pensar de que forma esse saber está sendo tratada nas escolas e nas universidades, espaços privilegiados para a inserção dos estudantes no saber matemático.

É cada vez mais frequente a denúncia da elitização da Matemática ${ }^{4}$ entre os pesquisadores e professores de disciplinas matemáticas e de disciplinas que necessitam dos fundamentos da Matemática como suporte. Isto é, a não aquisição dos conhecimentos matemáticos não está apenas impedindo o sujeito de apreender tais conteúdos e lidar com eles matematicamente, mas também, de apreender e aprender disciplinas como a Física, a Química, a Estatística, entre outras, pois estas necessitam do suporte matemático.

Entretanto, é mais comum encontrarmos pessoas com sintomas de "Matofobia" 5 ", que pessoas que transitam pelo mundo da Matemática sem problemas. Assim, é importante mapearmos a origem dessa situação que vem, historicamente, impedindo o sucesso dos estudantes em tal disciplina.

A escola brasileira tem como parâmetro avaliativo de inteligência um enfoque apoiado em uma visão de homem do início do século $\mathrm{XX}$, em função da qual se costuma avaliar a inteligência a partir de duas amplas categorias de competências: a verbal, revelada pela capacidade de expressão e uso conveniente das palavras, e a matemática, definida pela capacidade de solucionar problemas, desenvolvidos por meio de uma percepção espacial de objetos concretos (NORONHA; FREITAS; OTTATI, 2002). Contudo, atualmente, podemos nos calcar em olhares outros que salientam aspectos diversificados referentes ao desenvolvimento humano.

Então, salientamos que historicamente a Matemática tem sido considerada como uma disciplina formal, universal e descontextualizada, com "verdades eternas", obtidas pelo poder da lógica, lidando com um conjunto articulado de conceitos abstratos, caracterizando-se como uma área de conhecimento institucionalizado. Porém, tal

4 Processo no qual considera que a Matemática não é para todos, apenas para "mentes privilegiadas". 5 Medo da matemática, cf. Nimier, 1988. 
disciplina tem sido responsável em muitos países por uma significativa parcela de fracasso escolar (ROBERT, 1998; TAYLOR,1999; HUILLET; MUTEMBA, 2000).

A presença e importância da Matemática na escola é consequência de sua presença na sociedade e, portanto, às necessidades matemáticas que surgem na escola deveriam estar subordinadas às necessidades matemáticas da vida em sociedade como um todo, tornando os usuários, dessa área de conhecimento, habilitados para tratar com a mesma em todos os momentos em que tais conhecimentos fossem solicitados. Ou seja, a Matemática precisa habilitar os cidadãos a resolver problemas cotidianos, formulandoos e agindo matematicamente. Isso implica em capacitar os estudantes a lidar com uma complexidade cada vez maior, à medida que progridem de um nível para outro dentro do sistema educacional, em qualquer área de formação. Para isso, no caso da Matemática, se faz necessário que os estudantes compreendam as estruturas, as ideias e os métodos matemáticos e não simplesmente apliquem fórmulas ou algoritmos.

Os Parâmetros Curriculares Nacionais (BRASIL, 1998, p. 09) referentes à Matemática do Ensino Médio comenta que: “[...] No Ensino Médio, quando nas ciências, torna-se essencial uma construção abstrata mais elaborada, os instrumentos matemáticos são especialmente importantes". Esta afirmação afiança a importância e a necessidade da aprendizagem matemática, não só como 'ferramenta' para resolução de problemas cotidianos, mas também, como formadora do pensamento abstrato, dando condições aos estudantes de projetarem-se para situações em que não haja ancoragem nos objetos concretos.

Tal documento mostra claramente que a Matemática, mais que o suporte científico ao qual está intimamente vinculada, deverá também capacitar os estudantes para que eles possam analisar, argumentar, relacionar e interpretar fatos, ideias, fenômenos sociais e científicos etc. Assim, ajudar na formação de sujeitos críticos com ferramental técnico-científico capaz de conduzi-los a pensar e intervir na realidade dentro e fora da escola.

Apesar do que vêm apontando os Parâmetros Curriculares para o Ensino Médio é perceptível o grande número de estudantes que fracassam ao ingressarem no ensino superior, em cursos que exigem certo domínio das disciplinas "científico-tecnológicas" (Matemática, Física, Química e Biologia). Tal fato é apontado, por exemplo, na pesquisa desenvolvida na Universidade Estadual de Londrina (estado do Paraná) por Arruda e Ueno (2003). 
Esses autores mostram que muitos dos estudantes que entram no curso de Física da universidade supracitada, acabam desistindo por enfrentarem diversos tipos de problemas, com relação à complexidade dos problemas apresentados e a real dificuldade em enfrentar a quantidade de itens de conteúdo que "devem" ser trabalhados em cada semestre letivo. Também, os autores comentam que os conteúdos apresentam um nível de complexidade inédito para os estudantes, exigindo enorme esforço e disponibilidade de tempo, influenciando negativamente na sua permanência no curso em questão.

Outro trabalho similar é o de Santos (1994), que investigou as possíveis causas de desistência e reprovação, na disciplina de Cálculo Diferencial e Integral I, em dezessete cursos de graduação da Universidade Federal do Ceará. O estudo foi realizado com 196 estudantes dessa universidade, tendo encontrado como principal resultado que, apesar dos estudantes se considerassem com bom desempenho em Matemática no ensino médio tinham um fraco desempenho, constatado pelo autor, na disciplina de Cálculo, como resultado de uma deficiente formação básica em Matemática. Comentando tal conclusão, o autor supracitado acrescenta ainda a pobreza e o conservadorismo pedagógico na forma como as aulas seriam ministradas, o que tornaria mais grave o quadro.

Esses estudos supõem a existência de certo desnível ou não-compatibilização entre a Matemática no nível médio e no ensino superior. Tal desnível parece decorrer de dois tipos de fatores: deficiência, pura e simples, de conteúdo (não se está ensinando no ensino médio o mínimo de conhecimentos que deveria ser ensinado), e mudança abrupta de contrato didático (o ambiente psicossocial de funcionamento da sala de aula de Matemática do ensino superior divergiria, contratualmente, do ambiente de ensino do nível médio).

O primeiro grupo de fatores (déficit de ensino) é encampado em várias análises, como se pode depreender da leitura da Lei de Diretrizes e Bases da Educação Nacional (LDBEN/96), no artigo 35, item I, que salienta que o Ensino Médio tem como finalidade: "a consolidação e o aprofundamento dos conhecimentos adquiridos no ensino fundamental, possibilitando o prosseguimento de estudos".

O segundo se refere propriamente ao que acontece no intramuros da sala de aula gestada por um professor que tem expectativas em relação aos alunos, e alunos que têm expectativas em relação ao professor a partir de um saber envolvido, que nesse caso é o saber matemático. 


\section{Ensino da Matemática: quais os aspectos envolvidos nesse processo?}

Dentre as várias pesquisas sobre o tópico ensinar e aprender Matemática, mencionamos a de Da Rocha, Falcão e Meira (1994), que explica que ensinar Matemática tem, historicamente, significado transferir princípios, algoritmos e conceitos gerais, cuja articulação caberia ao aprendiz. Logo, ensinar pressupõe a transmissão de conhecimento acumulado historicamente e preparado institucionalmente para o ensino ("curricularizado" e normatizado para a transmissão escolar), cabendo ao professor gerir esse processo. Mas, espera-se tradicionalmente que o estudante seja cognitivamente "capaz" de dar conta de seu papel, articulando o conhecimento que lhe é ensinado adequadamente. Esse ensinar, que permeia nossas escolas, com relação à Matemática, para Silva (2002), tem sido insuficiente para proporcionar aos estudantes os meios de significação da informação disponível na sociedade.

Apesar disso, observa-se que na história da humanidade, nunca tivemos tantos cientistas como nos tempos atuais; o avanço científico e tecnológico, produzido por estes cientistas e profissionais de áreas mais distintas, incluem setores que mesmo não sendo diretamente vinculados a uma formação matemática específica utilizam-se da Matemática de certo nível de sofisticação (como é o caso da utilização, por psicólogos, de algoritmos estatísticos de descrição multidimensional). Isto denota que em todos os setores da sociedade os indivíduos, mesmo aqueles com "passado" escolar de reprovação em Matemática estão cotidianamente ressignificando esse conhecimento e tornando-o uma ferramenta útil, interessante e importante no seu dia a dia (o que não os impede de continuarem desprezando e detestando a matemática acadêmica, aquela que foi, e é "ensinada" na escola, e da qual têm péssima recordação).

Resumindo, apesar de a escola ser considerada como o lugar por excelência onde se realiza a educação e, sendo proposição dessa educação habilitar os integrantes da sociedade a tomarem posse de um corpo de conhecimento historicamente acumulado como um patrimônio cultural e a ser compartilhado, percebe-se que é também um espaço em que há mais rupturas que continuidades no processo de ensino.

Vários pesquisadores da área de Educação Matemática (ROBERT, 1998; TAYLOR, 1999; HUILLET; MUTEMBA, 2000, entre outros) já chegaram a essas conclusões e atualmente buscam formas de ressignificar conteúdos com o propósito de tornar mais claro para os estudantes à importância de cada um para que realmente exista aprendizagem. Também há que busque nas organizações de sala de aula aspectos 
relevantes para o desenvolvimento do fenômeno educacional situado nesses espaços.

\section{Formação de professores universitários de Matemática: algumas reflexões}

Apesar das sucessivas críticas ao ensino tradicional e de todos os avanços alcançados em pesquisas na área da Educação Matemática ${ }^{6}$ voltadas para a melhoria da prática pedagógica do professor e, consequentemente, favorecendo a aprendizagem matemática dos estudantes, percebe-se que pouco mudou, ou seja, o ensino baldista ${ }^{7}$ ainda é amplamente utilizado nas escolas e nas universidades, pois há certa dificuldade em transpor os resultados obtidos com esses estudos para aplicação concreta em sala de aula (CÂMARA DOS SANTOS, 2009). Tal fato favorece o distanciamento progressivo $^{8}$ entre as pesquisas desenvolvidas e a realidade da sala de aula.

Tal distanciamento consiste na dificuldade de articulação entre os resultados obtidos nas pesquisas educacionais e a realidade em sala de aula, ocasionando um empilhamento de reflexões advindas de pesquisas sem que com isso seja direcionado ao ambiente escolar. Para tanto, o distanciamento progressivo pode ser percebido com muita ênfase também nas universidades brasileiras, situando fortemente no âmbito da Matemática mais especificamente.

Desta forma, há um problema na maneira como a Matemática é ensinada nas escolas brasileiras. Isto se justifica pelos conteúdos que são trabalhados em sala de sala, que parecem ser desinteressantes, inúteis, e obscuros para muitos estudantes. Sobre esse assunto, se discute que:

[...] a grande maioria dos conteúdos escolares não é, de fato, utilizada ou aplicada pelo aluno no seu cotidiano. Perde-se, assim, a oportunidade de reconhecer que o aluno traz consigo, para a sala de aula, uma bagagem cultural rica em conhecimentos matemáticos que podem ser o ponto de partida para a formação e ampliação desses conhecimentos (CARDOSO, 2008, p.5).

É importante destacar que está problemática ocorre tanto na educação básica como no ensino superior. Dessa forma, quando falamos em pesquisas educacionais ou em formação continuada, não nos remetemos apenas aos professores dos ensinos

6 É importante lembrar, entretanto, que ao se assumir por referência o discurso teórico da Educação Matemática, deve-se ter ciência de que o conteúdo curricular é resultado de inúmeros tensionamentos sociais e políticos que definem suas conformações. Não há outro modo de compô-los senão por decisão dos agentes sociais. Desta feita, não se pode tratá-los de modo acrítico ou apolítico como se estivessem presentes nas escolas e universidades por acaso. Ao se criticar o conjunto de conteúdos escolares e/ou universitários há de se problematizar sua formação como resultado de negociações e mobilizações sociais ou, ao menos, assumir que isso ocorre por inúmeras contingências políticas, econômicas e socioculturais. 7 Cf. Câmara dos Santos (2002).

8 Cf. Câmara dos Santos (2009). 
fundamental e médio, mas também, estamos incluindo os docentes do ensino superior, pois estes profissionais também vivenciam inúmeras demandas e dificuldades referentes aos processos de ensino e de aprendizagem da Matemática, que podem influenciar na permanência e desistência dos graduandos nos cursos superiores.

Por muitos anos, se argumentava que a maioria dos professores não tinha acesso às informações geradas nos estudos e pesquisas que englobavam os tópicos de ensino e de aprendizagem na Matemática. Isto é, os resultados obtidos com as pesquisas educacionais mostravam que os resultados de estudos acerca do ensinar e do aprender matemático não chegavam às salas de aula dos professores que trabalhavam com a Matemática no ensino superior. Desta forma, o conhecimento construído com tais estudos ficava restrito a espaços fora das universidades, muito embora fossem produzidos nas universidades, ambiente de excelência para se fazer ciência. Tal fato representava um grande obstáculo para a aplicação das experiências estabelecidas nestes trabalhos.

Presentemente, há diversas opções pelas quais os professores podem ter acesso aos dados das pesquisas, principalmente em eventos científicos (congressos, encontros, simpósios, etc.), a exemplo da CIAEM (Conferência Interamericana de Educação Matemática), do SIPEM (Seminário Internacional de Pesquisa em Educação Matemática), do SIPEMAT (Simpósio Internacional de Pesquisa em Educação Matemática), do ENEM (Encontro Nacional de Educação Matemática), dos EREM (Encontros Regionais de Educação Matemática) etc., nos quais tais profissionais têm a possibilidade de participarem de diversas atividades (minicursos, palestras, mesasredondas, comunicações orais, entre outros) realizadas por pesquisadores de todas as partes do país e de outros países, tornando desta forma, um fórum de discussões e socialização de experiências educacionais.

Assim, afirma-se que:

Atualmente, a maior parte da população tem acesso às informações com
muita facilidade. As crianças e adolescentes recebem estímulos diferenciados
de antigamente, pois estão constantemente em contato com as novas
tecnologias, o que resulta em reações e aprendizagens diferenciadas. Tais
realidades exigem das escolas e dos educadores práticas pedagógicas mais
motivadoras, como músicas, danças, brincadeiras, jogos, teatros, enfim
atividades lúdicas que estimulem os educandos a construírem uma
aprendizagem mais significativa (ASCOLI; BRANCHER, 2006, p.1).

Ressalta-se que na atualidade, com o grande avanço tecnológico, temos a disposição um grande leque de informações, das mais variadas, obtidas apenas com um simples clique do mouse do computador, assim, tantos professores como alunos podem 
ter acessos a esses subsídios. Entretanto, o que se nota é que muitos professores não conseguem articular os resultados das pesquisas educacionais com o contexto de sua sala de aula. Tal fato ocorre provavelmente pela ausência de adequadas políticas públicas, bem como pela falta de um programa nacional de formação continuada universitária, que possibilite uma sólida reflexão sobre a prática pedagógica desses profissionais do ensino superior.

A intenção desse estudo não é culpabilizar os professores já tão sobrecarregados por seus afazeres e questões intra e intersubjetivas. Pois, em termos da didática não interpretamos questões como essa de modo unilateral ou linearmente, haja vista tratar-se de tema complexo, exigindo uma perspectiva teórica e ferramental analítico também complexo para dar o devido tratamento ao caso. Devemos atentar para fatores políticos (gestão político-governamental que visa manter o status quo e que tenciona a ação docente no sentido da manutenção das desigualdades e supressão de críticas ao sistema), econômicas (relacionadas ao tempo disponível dos professores para investirem em experimentações e adaptações de resultados de pesquisas nas salas de aula) e culturais (manifestação do habitus docente de reprodução de ações e discursos que estiveram presentes em suas próprias formações, o que dificulta a sua utilização de novas técnicas e metodologias de ensino, bem como a carência de pesquisas e trabalhos voltados às problemáticas e necessidades específicas relacionadas à realidade local dos professores e alunos). Estes são apenas alguns dos aspectos necessários para uma apreciação complexa do tema em tela.

Em relação ao distanciamento progressivo, podemos verificar que ele ocorre desde o ensino básico até o ensino superior. No caso dos cursos de licenciatura em Matemática, parte considerável do corpo docente é formada por bacharéis em Matemática (ou possuem mestrado e doutorado em "Matemática Pura"), então, sua própria formação universitária, em geral, pode não ter possibilitado uma reflexão adequada sobre a prática pedagógica. Desta forma, abre-se aqui uma nova vertente a ser trabalhada na formação continuada do professor de Matemática, a prática pedagógica dos docentes "não licenciandos", buscando impulsionar reflexões que ultrapassem o modo do fazer tradicional tão comum nas salas de aula no ensino superior.

Sobre a metodologia e didática docente praticada no ensino da Matemática, é fato que entre a maioria dos professores do ensino superior (e também os da educação básica) o ensino baldista, como dito anteriormente, é bastante evidente, no qual há uma ênfase na memorização dos conteúdos escolares e na repetição mecânica do que se 
"estudou" em sala de aula, sem a preocupação do real entendimento (compreensão/aprendizagem) pelo aluno, o que pode também favorecer o fracasso na Matemática e, posteriormente, abandono do curso.

Geralmente, quando é discutido sobre a formação de professores, reflete-se que:

\begin{abstract}
Quando tratamos do assunto "formação de professores", pensamos imediatamente na formação para a docência nos ensinos fundamental e médio, raramente remetemos tal pensamento à formação de professores universitários, causa uma impressão de que para este nível não é necessário uma formação. Porém, uma das críticas mais comuns dirigidas aos cursos superiores diz respeito à didática dos professores universitários, ou seria melhor dizer, à falta dela (UTRERA, 2011, p.5).
\end{abstract}

A crítica feita por Utrera (2011), em relação ao tratamento conferido pelos professores universitários de Matemática é legítima, contudo, a assertiva ao final da reflexão - "a falta dela"-, não é de ajuda a quem pretenda promover uma composição crítica em educação, visto não haver de maneira alguma falta de didática por quem quer que seja que venha assumir a posição docente no ato de ensinar. Fato é que podem manifestar transposições pouco reflexivas, assumir o protagonismo e centralidade das ações educativas, empregar a instrumentalização diretiva dos conteúdos em detrimento de uma dinâmica problematizadora e investigativa que promova a construção do conhecimento pelos alunos, o que se manifesta por relações geralmente distanciadas entre professor e aluno, o que tende a inviabilizar os processos dialógicos de ensino e avaliação. Estas características são manifestações didáticas epistemologicamente situadas e histórico e culturalmente determinadas, jamais ausência de didática.

O professor de nível superior necessita desenvolver a capacidade reflexiva inerente às articulações entre o fazer e o pensar, em sua prática pedagógica, em especial, acerca dos processos didáticos e metodológicos, enfatizando a promoção dos subsídios necessários à aprendizagem aos estudantes, favorecendo, assim, a atitude de aluno/pesquisador, logo, incentivando a continuidade dos estudos, e não sentimentos de medo e desistência da Matemática.

Como citado anteriormente, a maioria dos professores de Matemática dos cursos de Licenciatura em Matemática é constituída por bacharéis, mestres e doutores em Matemática. Contudo, tais profissionais, geralmente, lecionam as disciplinas como se estivem formando apenas bacharéis, enquanto que os aspectos referentes à formação de professores nem sempre é discutida por esses docentes. Aqui não estamos querendo dizer que na licenciatura não se deve estudar os conteúdos matemáticos na mesma "intensidade" do bacharelado. Todavia, reforçamos que para ser professor de 
Matemática é necessário tanto o conhecimento do conteúdo ${ }^{9}$ como o conhecimento pedagógico do conteúdo ${ }^{10}$.

Além disso, é imprescindível refletir melhor sobre tal cenário, visto que proporcionalmente às queixas e aos resultados evidenciados em pesquisas, não se tem obtido o êxito esperado nem na formação de matemáticos, visto os acadêmicos possuírem sérias deficiências de base que obstaculizam a compreensão dos conteúdos matemáticos do ensino superior. Logo, a evasão e a reprovação de estudantes também ocorrem nos cursos de bacharelado em Matemática, não se limitando apenas aos cursos de formação de professores. O que reforça a necessidade de se investigar de forma mais profundada sobre esse fenômeno.

Desta forma, evidencia-se que muitos dos problemas existentes na educação atual são creditados aos professores e suas práticas reprodutivista, a-crítica, não reflexiva, antiquada, pouco transformadora, etc. (SANTOS, 1994; PIMENTA; ANASTASIOU, 2002; MALTA, 2004, entre outros). Entretanto, é preciso reconhecer que muito do que acontece em sala de aula deve-se ao padrão de formação inicial desses professores, não se podendo, portanto, focar em responsabilidades do professor, esquecendo-se do quadro institucional de formação e exercício profissional do mesmo.

Não são poucos os pesquisadores que buscam através de seus discursos incentivarem um processo de revisão e atualização dos cursos de formação de professores e mesmo das condições de trabalho destes, em todos os níveis de escolarização, mostrando que, mais que ampliação quantitativa de instituições de nível superior, existe a necessidade de se investir na qualidade, pois o sujeito que procura se qualificar através dos cursos de formação, muitas vezes, não consegue nem adquirir a competência do saber da área de atuação, muito menos o saber pedagógico inerente e necessário à profissão.

Antes de ser uma "bênção" da democratização do ensino, os cursos de formação de professores são responsabilizados pela baixa qualidade da educação nacional, tornando-se, em muitos casos, motivo de gracejo da população, pois há o estereótipo de que abraçam a profissão docente aquelas pessoas que não se dariam bem em profissões que exigissem saberes mais específicos, como Direito, Engenharia, Medicina ${ }^{11}$ etc.

9 Cf. Shulman (1986).

10 Cf. Shulman (1986).

11Nesse sentido, diz-se, popularmente, que "quem sabe faz, quem não sabe ensina" ... 
É importante deixar claro tal fato se trata de uma parcela da opinião pública, e não possui sustentação científica. Tal assertiva é pejorativa e pouco consistente, haja vista que as licenciaturas são cursos de profissionalização superior altamente complexos e de saberes específicos tal qual qualquer outra graduação.

Ser professor demanda a articulação de saberes específicos das áreas de conhecimento e conhecimentos didáticos-pedagógicos, como salientam Pimenta e Anastasiou (2002), acerca das transformações das práticas docentes. Elas afirmam que tais práticas só se realizarão se o professor ampliar sua consciência sobre a própria prática, a de sala de aula e a da escola como um todo, o que pressupõe conhecimentos teóricos e críticos sobre a realidade. Enfatizando o que foi sugerido: a transformação da prática do professor decorrerá da ampliação de sua consciência crítica sobre essa mesma prática.

Entende-se que a democratização do ensino passa pelo desejo de mudança dos professores, por sua formação, por sua valorização profissional e por suas condições de trabalho. Vários são os pesquisadores que têm defendido a importância do investimento no desenvolvimento profissional da docência como um todo e da docência superior em particular.

A formação do professor deve ser antes de tudo epistemológica, ou seja, devendo-se reconhecer a docência como um campo de conhecimentos específicos necessários para a atuação dos agentes com coerência e clareza do fazer pedagógico cotidiano. Assim, a docência se constitui num campo específico de intervenção profissional na prática social.

Pimenta e Anastasiou (2002) salientam que tal reflexão e prática não são utilizadas em muitos cursos superiores, nos quais, pesquisadores dos vários campos de conhecimento como historiadores, químicos, filósofos, biólogos, cientistas políticos, físicos, matemáticos, artistas, etc. e profissionais de outras áreas de conhecimento como médicos, dentistas, engenheiros, advogados, economistas, etc; adentram o campo da docência como decorrência natural dessas atividades e por razões e interesses vários. Eles trazem os conhecimentos profissionais, porém não têm em sua formação os aspectos pedagógico-didáticos, logo, na maioria das vezes, não se questionam sobre os saberes próprios do ser professor. Semelhantemente, as instituições que os acolhem o fazem por serem o que são, desobrigando-se de torná-los professores. Esta situação gera traumas tanto no profissional/pesquisador-professor quanto no processo de ensino e aos seus resultados. 
A ideia, aqui, não é de apontar deficiências em relação as ações dos profissionais e/ou instituições, mas, de valorizar a formação e aperfeiçoamento dos docentes do ensino superior, buscando uma prática reflexiva e menos traumática para os envolvidos, ou seja, alunos e professores.

Ser professor requer saberes e conhecimentos científicos, pedagógicos, educacionais, sensibilidade, indagação teórica, criatividade para encarar as situações ambíguas, incertas, conflituosas no contexto escolar. É da natureza da atividade docente proceder à mediação reflexiva e crítica entre as transformações sociais concretas e a formação humana dos alunos, questionando os modos de pensar, sentir, agir e de produzir e distribuir conhecimentos.

Nos cursos de formação de professores é muito comum enfatizarem-se os saberes em detrimento dos deveres que os professores devem assumir junto aos seus alunos, ou seja, o dever de estar sempre atualizados com as pesquisas de sua área de conhecimento e com aquelas que os capacitam na docência. O dever de assegurar aos seus alunos a condição de cidadania que perpassa o ato próprio do aprender; o dever de assegurar uma aprendizagem significativa, fazendo-os perceber a importância do conhecimento científico-formal em suas atividades cotidianas.

Ao problematizar e analisar as situações da prática social de ensinar, o professor utiliza o conhecimento elaborado das ciências, das artes, da filosofia, da pedagogia e das ciências da educação como ferramenta para a compreensão e a proposição do real, tornando o trabalho docente impregnado de intencionalidade, pois este visa à formação humana por meio de conteúdos e habilidades, de pensamento e ação, o que implica escolhas, valores, compromissos éticos. Isso significa introduzir objetivos de natureza conceitual, procedimental e valorativa, em relação aos conteúdos das disciplinas que o professor ensina; transformar o saber científico ou tecnológico em conteúdos formativos; selecionar e organizar conteúdos de acordo com critérios lógicos e psicológicos, em função das características dos alunos e das finalidades do ensino; utilizar métodos e procedimentos de ensino específicos, inserindo-os em uma estrutura organizacional em que participe de decisões e ações coletivas. Por isso, para ensinar, o professor precisa de conhecimentos e práticas que ultrapassem o campo de sua especialidade.

Igualmente, diante do exposto, recomenda-se que o professor universitário deva utilizar de uma didática adequada, pensada e repensada nos estudantes (mas para isso é necessário fazer uma reflexão sobre o seu fazer pedagógico, fazendo uso dos resultados 
obtidos por pesquisas educacionais, pois tal fato também é uma maneira de se fazer formação continuada, que por sinal, possuem uma grande diversidade, seja econômica, social e cultural, tornando-se, deste modo, um professor que orienta e acompanha o aluno durante seu percurso na universidade, combatendo a reprovação e a desistência.

\section{Procedimento Metodológico}

Este estudo teve como objetivo discutir sobre os fatores que contribuem para o sucesso e o fracasso nos cursos de Licenciatura em Ciências (Habilitação em Matemática) e Matemática de um centro acadêmico vinculado a uma Instituição pública de Ensino Superior (IES) do Estado da Paraíba, Brasil. Nessa direção, ele apresenta uma abordagem qualitativa, pois concordamos com Augusto, Souza, Dellagnelo e Cario (2013, p.3), quando afirmam que "a pesquisa qualitativa envolve uma abordagem interpretativa do mundo, o que significa que seus pesquisadores estudam as coisas em seus cenários naturais, tentando entender os fenômenos em termos dos significados que as pessoas a eles conferem".

Participaram desta investigação 22 alunos dos cursos de Licenciatura em Ciências ${ }^{12}$ com Habilitação em Matemática (entre o $6^{\circ}$ e $10^{\circ}$ períodos) e de Licenciatura em Matemática ${ }^{13}$ ( $3^{\circ}$ e $4^{\circ}$ períodos), entre 2011 e 2013 (período da pesquisa). Esses estudantes já tinham cursado a disciplina de Cálculo Diferencial e Integral I na época da produção dos dados. A faixa etária dos participantes variava entre 20 e 30 anos de idade. Também, 10 licenciandos eram do sexo feminino e 12 do masculino. Além disso, a maioria deles já atuavam como professores da educação básica.

Neste artigo, serão omitidos os nomes dos participantes do estudo, então, eles serão identificados pela numeração indo arábica, isto é, teremos de 01 até 22. Além disso, não será realizada referência ao nome da universidade, pois o interesse desse estudo não foi a realização de uma avaliação institucional.

Para isso, utilizou-se como instrumento de coleta de dados um questionário que foi aplicado com os discentes supracitados, o qual objetivou obter informações sobre notas no vestibular, autoavaliação de desempenhos dos alunos na educação básica e no ensino superior, autoconceito dos estudantes. Dentre as diversas perguntas analisar-se-á

12 No curso de Ciências, a disciplina de Cálculo I era oferecida no $5^{\circ}$ semestre.

13 No curso de Matemática, a disciplina de Cálculo I é ofertada no $2^{\circ}$ semestre. Sendo que a turma "mais avançada" encontrava-se no $4^{\circ}$ período. 
aquela que suscitou discussões acerca dos fatores que contribuem para o sucesso e o fracasso dos licenciandos nos cursos ora estudados.

Com base nos depoimentos dos participantes registrados no estudo, foram categorizados os fatores intervenientes no sucesso e no fracasso dos mencionados cursos e, desse modo, a categorização apresenta mais coerência às reflexões do estudo. No Quadro 1, são apresentados os fatores que compõem cada uma das classificações:

\begin{tabular}{|c|l|c|}
\hline Grupo & \multicolumn{1}{|c|}{ Fatores } & Classificação \\
\hline 1 & Esforço, motivação e estímulos próprios (pessoais) & Sucesso \\
\hline 2 & $\begin{array}{l}\text { Incentivo para o aprofundamento, com envolvimento em } \\
\text { atividades extracurriculares (projetos de pesquisa, extensão, } \\
\text { monitoria, etc.) }\end{array}$ & \multirow{2}{|c|}{ Fracasso } \\
\hline 3 & $\begin{array}{l}\text { Formação “inadequada” oferecida pela universidade e problemas } \\
\text { com o currículo vivenciado }\end{array}$ & \\
\hline 5 & Didática dos professores e abordagem tradicional do ensino \\
\cline { 1 - 2 } & $\begin{array}{l}\text { Falta de estímulo/motivação para a permanência e promoção no } \\
\text { curso }\end{array}$ \\
\hline 6 & Ausência de tempo para se dedicar aos estudos \\
\hline
\end{tabular}

Quadro 1: Fatores de sucesso e fracasso segundo os participantes

Fonte: Elaborado pelos autores

Alguns resultados serão discutidos a seguir.

\section{Análise e discussão dos dados produzidos}

Nesta sessão será analisada a resposta dos alunos que obtiveram posicionamento diferenciado da maioria, trazendo para a discussão contribuições relevantes para o descortinar dos fatores que contribuem para o sucesso e o fracasso dos licenciandos nos cursos ora estudados. Para isto far-se-á uma relação entre as diversas falas dos estudantes que responderam o questionário aplicado. Ainda, considerando a repetição dos argumentos elencamos aqueles que apresentavam diferentes conotações acerca do tema abordado, segundo a classificação apresentada no Quadro 1.

É importante salientar que utilizar-se-á um recorte elencando uma das questões analisadas devido ao grande leque de temas abordados na complexidade do instrumento de coleta utilizado. Assim, apresentar-se-á as análises desenvolvidas acerca da questão do questionário.

Com relação à questão que tratava dos fatores que são determinantes para o sucesso e o fracasso nos cursos aludidos, os estudantes questionados em sua grande maioria colocam a referência para o sucesso basicamente no esforço próprio, 
salientando a dedicação e a perseverança próprias, ou seja, o esforço particular como receitas para a realização de um bom curso (características do Grupo 1). Isto pode ser compreendido nas falas do aluno 01 ao se referir a [...] Força de vontade, fé e determinação. Esta fala é coadunada pelo aluno 02, quando salienta que é Justamente a dedicação nas resoluções de exercícios. Porque diferentemente das outras disciplinas, a aquisição dos saberes matemáticos se deve à prática diária e não somente ao que é exposto na aula. E o fracasso, advém da falta dessa dedicação. Há quem diga também que é necessário ter facilidade de compreensão.

Assim, a motivação e o estímulo pessoal (Grupo 1) se tornam o teor das considerações sobre o sucesso na universidade. Em outras palavras pode-se dizer que o sucesso deve-se ao esforço pessoal de cada um, enquanto que, implicitamente, o fracasso é atribuído a questões relacionadas à universidade e às "más" formações oferecidas por ela (Grupo 3).

Então, quando se discute a relação que os estudantes estabelecem com o fracasso, vários foram os fatores considerados como deflagradores dos insucessos ocorridos, com considerável peso na didática utilizada pelos professores formadores (Grupo 4), tópico este já explorado na questão anterior.

Contudo, acrescenta-se ao item ora analisado a falta de estímulo/motivação para a permanência e promoção no curso (Grupo 5), em problemas gerados pelos currículos vivenciados (Grupo 3), pela falta de tempo de dedicação aos estudos (Grupo 6), nos rendimentos abaixo da média em disciplinas chaves durante a execução das atividades acadêmicas desenvolvidas em sua formação, desconsiderando muitas vezes o nível de escolaridade na qual estão inseridos trazendo para os mesmos, atitudes e vícios vivenciados no ensino médio.

Assim, considera-se que dentre as várias pesquisas sobre o tópico ensinar e aprender Matemática, menciona-se a de Da Rocha Falcão e Meira (1994), que explica que ensinar Matemática tem, historicamente, significado transferir princípios, algoritmos e conceitos gerais, cuja articulação caberia ao aprendiz. Logo, ensinar pressupõe a transmissão de conhecimento acumulado historicamente e preparado institucionalmente para o ensino ("curricularizado" e normatizado para a transmissão escolar), cabendo ao professor gerir esse processo. Mas, espera-se tradicionalmente que o estudante seja cognitivamente "capaz" de dar conta de seu papel, articulando o conhecimento que lhe é ensinado adequadamente. Esse ensinar, que permeia nossas escolas, com relação à Matemática, para Silva (2002), tem sido insuficiente para 
proporcionar aos estudantes os meios de significação da informação disponível na sociedade.

Assim, é possível verificar na fala dos alunos os reflexos dos problemas elencados. O aluno 10 comenta que para o [...] Fracasso: pouco estudo e algumas disciplinas complexas. Já o aluno 12 argumenta que ter que trabalhar para se manter configura-se um fator impedidor da verdadeira inserção a vida acadêmica. Isto é percebido na fala desse estudante, [...] Para o fracasso: ter que trabalhar para se manter e com isso se afastar da vida acadêmica. Está reflexão permeia o discurso de vários outros estudantes, levando-os a considerar que o trabalho e o estudo se tornam incompatíveis com uma boa experiência no ensino superior, principalmente com relação aos cursos menos valorizados na sociedade.

Os estudantes dizem também que há uma necessidade de estímulo ao envolvimento em atividades acadêmicas extracurriculares (Grupo 2) que dariam suporte às aprendizagens de sala de aula, preenchendo, dessa forma, lacunas não aprendidas nos tempos pedagógicos. Inclusive refletindo que para ensinar ou servir como monitor de disciplina é preciso rever, logo, efetivamente aprender os conteúdos que serão alvos de atividade de monitoria.

Tal fato pode ser observado nas respostas dos alunos, como pode ser percebido na fala do Aluno 04 quando salienta que [...] A desmotivação que o próprio professor passa nos incentiva a desistir (fracasso). Já o aluno 12 argumenta que o incentivo para o aprofundamento (Grupo 2) é condição fundamental ao sucesso na universidade. Isto pode ser visto no discurso elaborado pelo mesmo, quando diz que: Para o sucesso: uma vida acadêmica que vá além das aulas nas disciplinas, com participação em projetos, produção de artigos e outros.

Este tópico se apresenta aqui como um quesito de grande importância, já que, em uma discussão mais ampla, a sala de aula é apenas mais um espaço de aprendizagem, principalmente no ensino superior que disponibiliza uma grande quantidade de oportunidade de inserção em outras atividades formadoras como a pesquisa acadêmica e de iniciação à docência, no caso das bolsas do Programa Institucional de Bolsas de Iniciação à Docência (PIBID) e, também as atuações em projetos de extensão, monitoria, entre outros espaços que sevem como ampliação e consolidação de aprendizagens.

Em outras palavras, os estudantes confirmam a necessidade de se envolver nas atividades acadêmicas com participação ativa em projeto de pesquisa, extensão e 
monitoria (Grupo 2), sendo essas atividades parte relevante e complementar às aprendizagens da sala de aula. Isto faz perceber que o tripé que forma a universidade, Pesquisa, Ensino e Extensão são indissociáveis na formação do estudante.

Outra possibilidade de reflexão sobre o fracasso no curso é ainda a presença maciça da abordagem tradicional nos cursos dos estudantes pesquisados (Grupo 4). Esta questão fica clara, segundo eles, em um trabalho em sala de aula muito mecânico e pouco reflexivo, levando os professores a focarem sua prática de ensino na reprodução e coleta daquilo que os estudantes conseguiram devolver em forma de "aprendizado". Está forma de abordar os conteúdos, não dá condições a uma aprendizagem reflexiva, logo, tornando-se um empecilho à continuidade dos estudos em novas etapas, tais como fazer um mestrado ou doutorado dentro da área discutida. Pimenta e Anastasiou (2002), argumentam acerca das transformações das práticas docentes, que tais práticas só se realizarão se o professor ampliar sua consciência sobre a própria prática, a de sala de aula e a da escola como um todo, o que pressupõe conhecimentos teóricos e críticos sobre a realidade. Enfatizando o que foi sugerido: a transformação da prática do professor decorrerá da ampliação de sua consciência crítica sobre essa mesma prática.

Contudo, evidencia-se que muitos dos problemas existentes na educação atual são creditados aos professores e suas práticas reprodutivista, a-crítica, não reflexiva, antiquada, pouco transformadora, etc. (SANTOS, 1994; PIMENTA; ANASTASIOU, 2002; MALTA, 2004, entre outros). Tal situação se torna complexa uma vez que na profissão de professor as reflexões cotidianas acerca da sua prática levam-no a transformar seu ethos e modus operandis conduzindo-o a reflexões para a construção de sua identidade enquanto professor. Tais reflexões que, fundamentarão sua prática pedagógica, o separará da reprodução de experiências enquanto estudante e o capacitará, no seu próprio processo de aprendizagem, para que realize a síntese de sua ação docente particular.

Com relação especificamente ao curso de Ciências $^{14}$, o baixo quantitativo de disciplinas referentes à Matemática que habilitariam o estudante para trabalhar com a disciplina nas escolas torna-se insuficiente e pouco capacitante tanto para o aprofundamento do labor diário em sala de aula, quando mediadores de conhecimento matemático, quanto para a busca de novos campos do saber matemático.

14 No curso de Ciências há apenas 14 disciplinas que formam a matriz curricular que dá suporte à formação matemática dos licenciandos, enquanto que no curso reformulado e desmembrado originando os cursos de Matemática, Física, Química e Biologia, ficando o curso de Matemática com 18 disciplinas que dão embasamento teórico aos conhecimentos dessa área. 


\section{Considerações finais}

A presente pesquisa teve por objetivo discutir sobre os fatores que contribuem para o sucesso e o fracasso nos cursos de Licenciatura em Ciências (Habilitação em Matemática) e Matemática de um centro acadêmico vinculado a uma Instituição pública de Ensino Superior (IES) do Estado da Paraíba, Brasil.

Nesse sentido, observou-se que os estudantes afirmam que para obter sucesso nos seus cursos é necessário ter dedicação e perseverança, assim, fica evidente que para eles, apenas o esforço próprio (Grupo 1) deveria ser o diferencial para um bom desempenho ao longo do curso na universidade. Por outro lado, o fracasso no curso é proporcionado, quase que exclusivamente, pela universidade, isto é, pela “inconsistente” formação oferecida por esta instituição (Grupo 3).

Tal reflexão se dá por ainda refletirmos em nossas formações as questões próprias relacionadas à meritocracia como forma de nos diferenciarmos enquanto profissionais bem ou mediocremente formados, essa lógica perpassa tanto o processo quanto o produto das formações, principalmente, com relação aos cursos de licenciaturas aqui analisados, remetendo a uma reflexão precária e muitas vezes falhas das práticas de sala de aula, as quais são vistas como únicos espaços de aprendizagem. Por isso como dito anteriormente é importante salientar que ser professor demanda a articulação de saberes específicos das áreas de conhecimento e conhecimentos didáticos-pedagógicos, como salienta Pimenta e Anastasiou (2002), acerca das transformações das práticas docentes.

Os fatores geradores do insucesso, discutido pelos licenciandos participantes da pesquisa apontam para aspectos didáticos e metodológicos docentes (Grupo 4), ausência de efetivos mecanismos estimuladores/motivadores para a continuação no curso (Grupo 5), currículos desarticulados (Grupo 3), pouco tempo necessário a dedicação aos estudos (Grupo 6), baixos rendimentos apresentados nas disciplinas em decorrência, por exemplo, de terem que conciliar estudo e trabalho, etc. Esses resultados coadunam com pesquisas anteriormente realizadas como a de Santos (1994) que apontava como uma das causas da desistência dos alunos a questão de prática tradicional dos professores da disciplina de Cálculo I. Enquanto que Arruda e Ueno (2003) mostraram que muitos dos estudantes que entram no curso de Física da Universidade Estadual de Londrina, acabam desistindo por enfrentarem diversos tipos de problemas com relação à 
complexidade dos problemas apresentados e à real dificuldade em dar conta da quantidade de itens de conteúdo.

Os graduandos discorrem, ainda, da necessidade da participação em atividades acadêmicas extracurriculares e extraclasses (Grupo 2), em resposta às aprendizagens de sala de aula. Desse modo, fica constatado que não é possível dissociar pesquisa, ensino e extensão na formação do licenciando.

Outra questão discutida pelos estudantes é a presença, ainda muito forte, do ensino tradicional por parte dos seus professores da universidade (Grupo 4). A prática pedagógica desses profissionais é caracterizada pela mecanização e memorização dos conteúdos abordados em sala de aula (ensino baldista), que na verdade, são reflexos da formação recebida desses docentes. Tal fenômeno tem dificultado a continuação dos estudos pelos estudantes, no que se refere ao mestrado e ao doutorado.

\section{Referências}

ARRUDA, S. M.; UENO, M H. Sobre o ingresso, desistência e permanência no curso de Física da Universidade Estadual de Londrina: algumas reflexões. Revista Ciência \& Educação, São Paulo, v. 9; n. 2, p. 159-175, 2003.

AUGOSTO, C. A.; SOUZA, J. P.; DELlAGNELO, E. H. L.; CARIO, S. A. F. Pesquisa Qualitativa: rigor metodológico no tratamento da teoria dos custos de transação em artigos apresentados nos congressos da Sober (2007-2011). Revista de Economia e Sociologia Rural, Brasília, v.51, n.4, p.1-12, out./dez. 2013.

ASCOLI, C. C. B.; BRANCHER, V. R. Jogos matemáticos: algumas considerações sobre os processos de ensino e aprendizagem. In: JORNADA NACIONAL DE EDUCAÇÃO, 2., 2006, Santa Maria. Anais... Santa Maria: Centro Universitário Franciscano, 2006. p.1-9. Disponível em:

<http://www.unifra.br/eventos/jornadaeducacao2006/2006/pdf/artigos/matem\%C3\%A1tica/JO GOS\%20MATEM\%C3\%81TICOS.pdf > Acesso em: 03 fev. 2016.

BRASIL. Lei no 9.394, de 20 de dezembro de 1996. Lei de Diretrizes e Bases da Educação Nacional. Diário Oficial [da] República Federativa do Brasil, Brasília, DF, 23 dez. 1996. Disponível em: <http://www.planalto.gov.br/ccivil_03/leis/L9394.htm> Acesso em: 03 fev. 2016.

BRASIL. Ministério da Educação. Parâmetros Curriculares Nacionais - Ensino Médio/Matemática. Brasília: MEC/SEF, 1998. Disponível em: <http://portal.mec.gov.br/seb/arquivos/pdf/ciencian.pdf> Acesso em: 03 fev. 2016.

CÂMARA DOS SANTOS, M. Algumas concepções sobre o ensino e a aprendizagem em matemática. Educação Matemática em Revista, Recife, v.9, n.2, p. 38-46, jan./ jun. 2002.

CÂMARA DOS SANTOS. O Cabri-Géomètre e o desenvolvimento do pensamento geométrico: o caso dos quadriláteros. In: BORBA, R.; GUIMARÃES, G. (Org.). A Pesquisa em Educação Matemática: repercussões na sala de aula, São Paulo: Cortez, 2009. p. 177-211. 
CARDOSO, E. R. Jogos matemáticos no contexto escolar. Trabalho de Conclusão de Curso. Maringá: Secretaria de Estado de Educação do Paraná, 2008.

DA ROCHA FALCÃO, J. T. MEIRA, L. A. A experiência matemática na escola de $1^{\circ}$ grau. Educação Matemática em Revista, v.1, n.2, p.37-42, 1994.

HUILLET, D.; MUTEMBA, B. The relation of mozambican secondary school teacher to a mathematical concept: the case of limits of functions. In: INTERNATIONAL MEETING OF PSYCHOLOGY OF MATHEMATICS EDUCATION, 24., 2000, Hiroshima. Annals... Hiroshima: Association of Psychology of Mathematics Education, 2000. p.1-8.

LIMA BORBA, V. M.; COSTA, A. P. Uma análise sobre a permanência e a desistência de licenciandos em matemática no centro de formação de professores da universidade federal de campina grande. In: ENCONTRO NACIONAL DE EDUCAÇÃO MATEMÁTICA, 11., 2013, Curitiba. Anais... Curitiba: Sociedade Brasileira de Educação Matemática - Regional Paraná, 2013a. p.1-16.

LIMA BORBA, V. M. Algumas reflexões sobre a concepção dos estudantes dos cursos de ciências e matemática acerca da importância da matemática e os reflexos que influenciam a desistência e a permanência no curso. In: ENCONTRO REGIONAL DE EDUCAÇÃO MATEMÁTICA, 4., 2013, Santa Cruz. Anais... Santa Cruz: Sociedade Brasileira de Educação Matemática - Regional Rio Grande do Norte, 2013b. p.1-10.

LIMA BORBA, V. M.; BRITO LIMA, A. P. A.; RÉGNIER, J. G. A questão da permanência e desistência dos estudantes de Licenciatura em Matemática no Brasil: estudo exploratório abordado pelo quadro da Análise Estatística Implicativa. In: RÉGNIER, J. G.; SLIMANI, Y.; GRAS, R (Org.). Analyse Statistique Implicative: Des sciences dures aux sciences humanies et sociales. Lyon: Association ARSA, 2015. p.646-669.

MALTA, I. Linguagem, leitura e matemática. In CURY, H. N. (Org.). Disciplinas matemáticas do ensino superior: reflexões, relatos, propostas. Porto Alegre: EDIPUCRS, 2004.

NIMIER, J. Les modes de rélations aux mathématiques. Paris: Méridiens-Klincksieck, 1988.

NORONHA, A. P. P.; FREITAS, F. A.; OTTATI, F. Parâmetros psicométricos de testes psicológicos de inteligência. Interação em Psicologia, Curitiba, v.6, n.2, p.195-201, jul./dez. 2002.

PIMENTA, S. G.; ANASTASIOU, L. G. C. Docência no ensino superior. São Paulo: Cortez, 2002.

RAFAEL, R. C. Cálculo Diferencial e Integral: estratégias adotadas por universidades para reduzir o percentual de reprovação/evasão na disciplina. In: ENCONTRO BRASILEIRO DE ESTUDANTES DE PÓS-GRADUAÇÃO EM EDUCAÇÃO MATEMÁTICA, 18., 2015, Juiz de Fora. Anais... Juiz de Fora: Programa de Pós-Graduação em Educação Matemática da UFJF, 2015. p. 1-12.

RAFAEL, R. C.; ESCHER, M. A. Evasão, baixo rendimento e reprovações em Cálculo Diferencial e Integral: uma questão a ser discutida. In: ENCONTRO MINEIRO DE EDUCAÇÃO MATEMÁTICA, 7., 2015, Juiz de Fora. Anais... Juiz de Fora: Programa de Pós Graduação em Educação Matemática. p. 1-10, 2015.

RISSI, M. C. MARCONDES, M. A. S. Estudo sobre a reprovação e retenção nos cursos de graduação - 2009. Londrina: UEL, 2011. 
ROBERTO, A. Outils d analyse des contenus mathématiques à enseigner au Lycée et L` Université. Recherches em didactique des mathématiques, v.18, n.2, p.139-190, 1998.

SANTOS, R. M. Avaliação do desempenho no processo de ensino-aprendizagem de Cálculo Diferencial e Integral I: o caso da Universidade Federal do Ceará. Dissertação (Mestrado em Educação) - Universidade Federal do Ceará, Fortaleza, 1994.

SHULMAN, L. S. Those who understand: knowledge growth in the teaching. Educational Researcher, Washington, US, v. 15, n. 2, p. 4-14, 1986.

SILVA, J. A. M. Educação matemática e exclusão social: tratamento diferenciado para realidades desiguais. Brasília: Plano Editora, 2002.

Recebido em: 20 de fevereiro de 2018.

Aceito em: 29 de março de 2018. 